6584

Research Article

Journal of Extension Education

Vol. 32 No. 4, 2020

DOI:https://doi.org/10.26725/JEE.2020.4.32.6584-6594

\title{
Assessing the Overall Efficiency of two technologies of Bangabandhu Sheikh Mujibur Rahman Agricultural University, Bangladesh
}

\author{
M.S. Islam Afrad ${ }^{1}$, A. Hossain Galib ${ }^{1}$, M. Enamul Haque ${ }^{1}$, M. Zakaria ${ }^{1}$ \\ M.H. Sakib ${ }^{1}$, M.M. Rahman ${ }^{2}$ and A.A. Shoily ${ }^{3}$
}

\begin{abstract}
A study was conducted to investigate the farmers' response on the performance of two specific Bangabandhu Sheikh Mujibur Rahman Agricultural University (BSMRAU) technologies viz. BU dhan1 and BU Hybrid lau1. In this connection, two districts of Northern Bangladesh were considered with 80 farmer respondents selected by simple random sampling technique to examine their responses on technology performance, adoption, impacts, associated limitations with possible suggestions and knowledge gap. Findings from this study reveal that the BU dhan 1 had a high adoption level. In contrast, BU Hybrid lau1 had a low level of adoption. BU dhan1 performed well with low complexities when it was cultivated in the field. The study further provides information that majority farmers showed low to moderate knowledge gap in cultivating both of these technologies. Moreover, dried empty grains and less market value were listed as major constraints faced by BU dhan 1 growers, while BU Hybrid lau1 growers suffered from severe virus attack during cultivation. Provisions of sufficient disease-free seed supply and proper training facilities were suggested by all the farmers interviewed.
\end{abstract}

Keywords: BSMRAU, Technology, Performance, Northern Bangladesh

\section{INTRODUCTION}

Bangladesh embraces regular agribusiness practices of agrarian societies for growing all kinds of agricultural crops to meet daily food demand in domestic markets (Quddus and Kropp, 2020).

Generally, the increasing population growth demands more agricultural land for food production and processing to meet dietary necessity (Guo et al.,2019). In addition, land demand increases faster for the rapid industrialization as a part of urbanization (Wanfu et al., 2019). Only crop intensification gives sufficient production to compensate the adverse effect of farmland transformation into infrastructure for residence and industry.

1. Faculty of Agriculture, Bangabandhu Sheikh Mujibur Rahman Agricultural University, Gazipur - 1706. Bangladesh.

2. EXIM Bank Agricultural University, Bangladesh.

3. Bangladesh Rice Research Institute, Bangladesh.

Received : 20-04-2020; Accepted : 13-07-2021 
Assessing the Overall Efficiency of two technologies of

Bangabandhu Sheikh Mujibur Rahman Agricultural University, Bangladesh

Unfortunately, every year, Bangladesh suffers from different climatic catastrophes, especially flood, considered responsible for reducing major crops production (Alamgir et al., 2019). Frequent occurrence of floods is responsible for the adverse effects on the country's natural resources, society and economy (Leya et al., 2020). Likewise, the northwest districts of Bangladesh are also included in the list of highly drought prone region (Alamgir et al., 2019). Drought is alleged for affecting the Boro rice production for changing climate in the future (Zinat et al., 2020). Those who were basically landless farmers have linked seasonal drought (which is an environmental driver) as persuading bad harvest in sharecropping. Failure to repay the microcredit (intended originally to bear the cost of farming) installments ultimately exposed the landless farmers to alleged harassment by the money-lending institutions (Kabir et al., 2018). In 2010, arable lands declined dramatically from $34 \%$ in 2005 to $8 \%$ in the study area although aquaculture land cover increased from 17 to $39 \%$ during the same time (Adnan et al., 2020). High productive crop varieties can only increase production in declined cultivable lands to feed the huge growing population in this delta. BSMRAU also introduced some high-quality crop varieties to the farms in different corner of the country. However, there are very few information about the BSMRAU technologies and data were very limited to upgrade a crop. By considering the conditions, overall advantages and acceptability of BSMRAU technologies such as BU dhan1 (Oryza sativa L., a variety of rice) and BU lau1 (Lagenaria siceraria, a hybrid variety of bottle gourd) were assessed. To draw clear ideas about the strength of these two technologies, their adoption, uses, impact, performance, knowledge gap, and problems were also calculated.

\section{METHODOLOGY}

\section{Study area}

The study was conducted in the northern part of Bangladesh. Bogura and Gaibandha districts are located in the northern territory of the country. Shibganj, upazila of

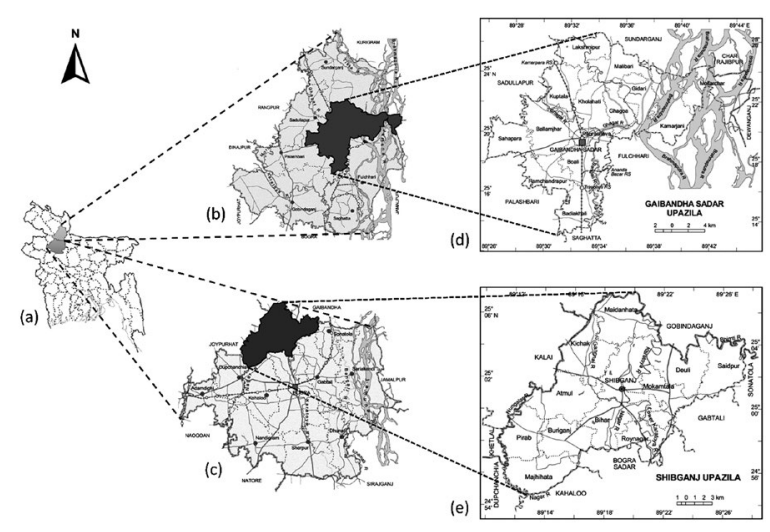

Figure 1. Map of the study area. (a) Location of the study areas in Bangladesh; (b) Gaibandha district with one study area; (c) Another study area of Bogura district; (d) and (e) are the areas of our interest, Gaibandha Sadar upazila and Shibganj upazila, respectively

Bogura, is a land of wide range of agricultural crops. Gaibandha Sadar upazila is in the middle of Gaibandha district and it is also significant place for agriculture too. Therefore, Shibganj and Gaibandha Sadar were selected for this study (Figure 1).

\section{Sampling}

Farmers cultivating BU dhan1 and BU Hybrid lau1 in the selected areas were the targeted population for the study. A 
suitable sampling technique was opted from a study of Rao (2016). Thereafter, a list of BU dhan1 growers was collected from the Rangpur Dinajpur Rural Service (RDRS), a Non-Government Organization (NGO) at Gaibandha Sadar. The number of enlisted farmers who grew BU dhan1 was 200. From the list of farmers, forty farmers (20\% of the population) were sampled randomly. Similarly, list of BU Hybrid lau1 growers was collected from "3S" seed company at Shibganj, Bogura. the total number of BU Hybrid lau1 growers was found to be 160 . Thereafter, 40 farmers (25\% of the population) were randomly selected as sample. Thus, a total of 80 farmers, 40 from each technology were selected as respondents of the study.

\section{Collection of Data}

An interview schedule was constructed for gathering relevant information to satisfy the objectives of the study. Data were collected from respondents by face-toface interview and rapport was established with the help of Sub-Assistant Agricultural Officer (SAAO) for getting true and correct information. The instruments contained both open and closed form of questions. A research instrument is usually said to be valid when the objectives of the study are reflected in the instrument and so, content validity of the instrument is very important. All possible precautions were taken to prevent bias and to maintain fidelity of the responses. Statements were recorded according to respondents' feedback and avoided to include any kind of instant judgement from the side of the interviewer. Nevertheless, the biasing effect of the interviewing or phrasing of questions was reduced to minimum as far as possible. Questions were asked in several possible ways until it was ascertained that the respondents could understand the question properly. If a respondent's response was not clear enough to reflect what she/he intended to mean, supplementary questions were asked for further clarification. Based on the comments and suggestions of experts, the content of the instrument was modified. The questions and statements contained in the schedule were simple, direct and understandable by the respondents. After filling up the interview schedule by obtaining information from a respondent, it was cross-checked twice to avoid missing information.

\section{Performance of Technology}

The performance of BSMRAU technologies in farmers' field was measured in terms of perceived five benefits like relative advantage, compatibility, complexity, trial ability and observability (Rogers, 2003). These five salient characteristics of technology were used with a view to determine their influence on adoption of these two technologies in this study. For example, to reveal the relative advantage of a technology, few qualities such as increased income, better marketability, ease of handling and better taste were considered. Similarly, some features i.e., social acceptability, adaptation to environment, personal compatibility, less input requirement were considered for getting farmers' response on compatibility. Likewise, handling difficulty, complicacy in understanding and additional input requirement were given importance 
Assessing the Overall Efficiency of two technologies of

Bangabandhu Sheikh Mujibur Rahman Agricultural University, Bangladesh

for estimating complexity of the technology. Further, additional time requirement, input requirement and additional cost involvement were examined for judging trial ability. Finally, vigor and better physical appearance were considered to ascertain observability.

\section{Adoption, Usage and Impact of Technology}

Adoption of a technology can be measured in different ways. However, a multidimensional adoption scale was used to measure the rate of adoption of a technology. The scale covers both duration and area in terms of practicing a particular technology. The dimensions were:(a) time of the introduction of the technology under study; (b) time of user's awareness about the technology; (c) time of adoption of the technology by the individual; and(d) proportion of the area covered by the technology during the period under survey has been employed in a modified form to assess The formula (Nasim et al. 2019) for calculating Adoption Quotient of selected BSMRAU technology:

$$
A Q=\frac{T_{1}}{T_{3}} \times \frac{T_{2}}{T_{3}} \times \frac{A_{1}}{A_{2}} \times 100
$$

where, $A Q$ denotes adoption quotient; T1 indicates the year from which the BSMRAU technology was introduced in the study area; T2 represents the year from whichthe user became aware of the BSMRAU technology; T3 is the year from when the BSMRAU technology was adopted by the user; $A 1$ indicates the actual area under BSMRAU technology during the surveyed year; $A 2$ is the potential area for cultivation under BSMRAU technology during the surveyed year; From the above formula the extent of adoption of those technologies were measured.

Adopted technology will be continued by a farmer if it contains sufficient desirable characteristics to make a profitable farming practice. Usage of a technology was measured based on continuation of the technology with a total duration (year) of farming. Number of years was counted to determine the usage of the technology. Thus, the year of introduction of the technology and the year of ending the practice among the farmers were investigated. Impact of a technology referred to the advantages of that innovation for the economy and production. Increment in total production was computed and the increased revenue from the technology was also estimated. Technology upgrades the lifestyle and socio-economic condition of a community. Therefore, annual earning increment is one of the signs of a good technology as a positive impact.

\section{Knowledge Gap}

Farmers' agricultural knowledge referred to the understanding and acquaintance on different agriculture related activities. To assess the respondents' knowledge gap in using BSMRAU technology, a scale was constructed including fifteen related questions to itemize their responses. Each question was written with similar weave length and was given two marks. Respondents were given full marks in case of correct response but given one mark for a feedback close to the correct answer. In case of incorrect answers, a score of zero (0) was given. Total marks obtained by a respondent 
were subtracted from thirty (30) to evaluate their knowledge gap. Because, a respondent answering all the fifteen questions correctly would score full marks i.e., 30. Knowledge gap was categorized into three groups following Naznin et al. (2018). The lowest and highest score of farmers' knowledge gap for both technologies were obtained as 3 and 24, respectively. Considering the range of the obtained score, farmers' knowledge gap was categorized as low $(\leq 10)$, medium (11-17) and high $(\geq 18)$.

\section{Focus Group Discussion (FGD)}

Focus group discussion is regularly used as a qualitative approach, to gain an indepth understanding of social issues (Nyumba et al., 2018). Through this approach the salient features of two BSMRAU technologies were explored. In the study area, two FGDs were arranged with 10 participants for every single technology to validate quantitative results. The relevant participants from user including different age groups viz. young, middle age, old age farmers; different educational levels viz. illiterate, primary and secondary education; various income groups like low medium and high-income group farmers in each location.

\section{Analysis of Data}

After collection of data, all the numeric values in the interview schedule were compiled. All the collected data were checked, coded and entered into the computer for analysis. Descriptive statistics viz. frequency distribution, mean and percentiles were computed for transforming collected data into the information in summarizing the findings of the study. In addition, data were categorized on the basis of the objectives of the study by considering mean, range and standard deviation. Two computer programmes such as Microsoft Excel 2016 and Statistical Package for Social Sciences (SPSS) ver. 25 were used for analyzing data. Analyzed data were presented in tabular forms to describe these elaborately for extracting the information accurately.

\section{FINDINGS AND DISCUSSION}

This section is structured into five subsections. Section 1 explores overall performance of BU dhan 1 and BU Hybrid lau1 at farmer level. Extent of adoption, usages and impact of these two technologies are shown in Section 2. Section 3 describes knowledge gap of the respondents on cultivation of these technologies. Section 4 includes the problems and suggestions identified by the farmers for both BSMRAU technologies. Section 5 gives evidences the nature of technologies through qualitative analysis, Focus Group Discussion (FGD).

\section{Performance of Technology}

The performance of both technologies, BU dhan 1 and the BU Hybrid lau1 was assessed by farmers' opinion in terms of technology's relative advantages, compatibility, complexity, trialability and observability, as shown in the Table 1. BU dhan1 offered remarkable advantages in taste, marketing, handing and income to the growers. Similarly, 'better taste', 'easy handling' and 'better marketability' were found as the characters of the BU Hybrid lau1.The compatibility assessment showed that in every case, $\mathrm{BU}$ dhan 1 showed greater 
Assessing the Overall Efficiency of two technologies of Bangabandhu Sheikh Mujibur Rahman Agricultural University, Bangladesh

Table 1.

Performance of BSMRAU Technologies

\begin{tabular}{|l|l|c|c|}
\hline \multirow{4}{*}{ Perceived attributes } & \multicolumn{2}{|c|}{ Indicators } & \multicolumn{2}{|c|}{ Respondents } \\
\cline { 3 - 4 } & & $\begin{array}{c}\text { BU dhan1 } \\
\%\end{array}$ & $\begin{array}{c}\text { BU Hybrid lau1 } \\
\%\end{array}$ \\
\hline \multirow{5}{*}{ Relative advantage } & 1. Increased income & 13.70 & 10.70 \\
\cline { 2 - 4 } & 2. Better marketability & 78.00 & 76.80 \\
\cline { 2 - 4 } & 3. Ease of handling & 80.50 & 76.60 \\
\cline { 2 - 4 } & 4. Better taste & 85.30 & 86.20 \\
\hline \multirow{5}{*}{ Compatibility } & 1. Social acceptability & 86.30 & 77.60 \\
\cline { 2 - 4 } & 2. Adaptation to environment & 84.70 & 75.30 \\
\cline { 2 - 4 } & 3. Personal compatibility & 82.10 & 77.60 \\
\cline { 2 - 4 } & 4. Less input requirement & 01.70 & 00.80 \\
\hline \multirow{4}{*}{ Trialability } & 1. Handling difficulty & 07.60 & 10.70 \\
\cline { 2 - 4 } & 2. Complicated to understand & 07.10 & 16.60 \\
\cline { 2 - 4 } & 3. Additional input requirement & 00.80 & 02.10 \\
\hline \multirow{2}{*}{ Observability } & 1. More time requirement & 02.30 & 03.00 \\
\cline { 2 - 4 } & 2. More input requirement & 04.60 & 06.30 \\
\cline { 2 - 4 } & 3. More cost involvement & 03.50 & 07.10 \\
\hline & 1. Vigor & 81.50 & 80.20 \\
\cline { 2 - 4 } & 2. Better physical appearance & 84.60 & 89.50 \\
\hline
\end{tabular}

performance. Farmers faced comparatively less complexity and trial ability when they cultivated BU dhan1 in their field. Most of the respondents believe that $\mathrm{BU}$ dhan1 is vigor, and have nice physical appearance. Similarly, majority confirmed good physical appearance and growth of BU Hybrid lau1.

\section{Extent of Adoption, Usage and Impact of Technology}

Results presented in Table 2 reveal that the adoption of BU dhan1 was medium to high (77.5\%). In contrast, $67.5 \%$ of respondents were belong to low adoption category of BU Hybrid lau1. More than $70.0 \%$ farmers had used BU dhan 1 technology for above 3 years. On the other hand, $60.0 \%$ of respondent farmers had used the BU Hybrid lau1 for a single year. The data on impact on increasing the yield and increment of income represent the same results that majority of the farmer experienced slight increase in the yield and income by implementing both technologies. Only around $10.0 \%$ respondents admitted high amount yield increase.

\section{Knowledge Gap}

An assessment on technical knowledge of the respondents related to the production of BU dhan1 and BU Hybrid lau1 
Table 2.

Extent of Adoption, Usage and Impact of BSMRAU Technologies

\begin{tabular}{|c|c|c|c|c|c|}
\hline \multirow{2}{*}{ Attributes } & \multirow{2}{*}{ Technology } & \multirow{2}{*}{ Categories } & \multicolumn{2}{|c|}{ Respondents } & \multirow[t]{2}{*}{ Mean } \\
\hline & & & No. & $\%$ & \\
\hline \multirow{6}{*}{ Extent of adoption } & \multirow{3}{*}{ BU dhan1 } & $\operatorname{Low}(\leq 50)$ & 09 & 22.5 & 73 \\
\hline & & Medium (51-75) & 14 & & 35.0 \\
\hline & & High $(>75)$ & 17 & & 42.5 \\
\hline & \multirow{3}{*}{ BU Hybrid lau1 } & $\operatorname{Low}(\leq 50)$ & 27 & 67.5 & 56 \\
\hline & & Medium (51-75) & 06 & & 15.0 \\
\hline & & High (>75) & 07 & & 17.5 \\
\hline \multirow{5}{*}{ Usage } & \multirow{3}{*}{ BU dhan1 } & Low ( $\leq 2$ years) & 05 & 12.5 & 3.6 \\
\hline & & Medium (3-4 years) & 30 & & 75.0 \\
\hline & & High (>4 years) & 05 & & 12.5 \\
\hline & \multirow{2}{*}{ BU Hybrid lau1 } & Low (1 year) & 24 & & 60.0 \\
\hline & & High (2 years) & 16 & & 40.0 \\
\hline \multirow{6}{*}{$\begin{array}{c}\text { Impact on increasing } \\
\text { the yield }\end{array}$} & \multirow{3}{*}{ BU dhan1 } & $\operatorname{Low}(\leq 10)$ & 19 & 47.5 & 13.2 \\
\hline & & Medium (11-20) & 17 & & 42.5 \\
\hline & & High $(>20)$ & 04 & & 10.0 \\
\hline & \multirow{3}{*}{ BU Hybrid lau1 } & Low $(\leq 10 \%)$ & 23 & 57.5 & 9.9 \\
\hline & & Medium (11-20\%) & 12 & & 30.0 \\
\hline & & High (>20\%) & 05 & & 12.5 \\
\hline \multirow{6}{*}{$\begin{array}{c}\text { Impact on increment } \\
\text { of income }\end{array}$} & \multirow{3}{*}{ BU dhan1 } & $\operatorname{Low}(\leq 5 \%)$ & 26 & 65.0 & 6.0 \\
\hline & & Medium (5-10\%) & 09 & & 22.5 \\
\hline & & High (>10\%) & 05 & & 12.5 \\
\hline & \multirow{3}{*}{ BU Hybrid lau1 } & Low ( $\leq 5 \%)$ & 34 & 85.0 & 3.7 \\
\hline & & Medium (5-10\%) & 04 & & 10.0 \\
\hline & & High (>10\%) & 02 & & 05.0 \\
\hline
\end{tabular}

Table 3.

Respondents' Knowledge Gap on BU dhan1 and BU Hybrid lau1 Cultivation

\begin{tabular}{|l|c|c|c|c|c|c|}
\hline \multirow{2}{*}{ Knowledge } & \multicolumn{3}{|c|}{ Respondents (BU dhan1) } & \multicolumn{3}{c|}{ Respondents (BU Hybrid lau1) } \\
\cline { 2 - 3 } & Frequency & Percent & Mean & Frequency & Percent & Mean \\
\hline Low $(\leq 10)$ & 7 & 17.5 & & 5 & 12.5 & \\
\cline { 1 - 3 } \cline { 6 - 7 } & 25 & 62.5 & \multirow{2}{*}{13.5} & 29 & 72.5 & \multirow{2}{*}{14.4} \\
\cline { 1 - 3 } \cline { 5 - 6 }$(11-17)$ & 8 & 20.0 & & 6 & 15.0 & \\
\hline
\end{tabular}


Assessing the Overall Efficiency of two technologies of Bangabandhu Sheikh Mujibur Rahman Agricultural University, Bangladesh

is displayed in Table 3. Moderate knowledge gaps (mean score 13.5 and 14.4 for BU dhan 1 and BU Hybrid lau1, respectively) on different agricultural operations were revealed for both technology users. Most of the BU dhan1 growers $(80.0 \%)$ had medium to low level of knowledge gap on its cultivation. Similarly, majority of the respondents (85.0\%) had low to medium level of knowledge gap in cultivation of BU Hybrid lau1.

\section{Constraints and Suggestions}

The major constraints and possible suggestions of the respondents' during implementation of these technologies are enlisted in Table 4. It shows that existence of dried empty grain was listed as the key problem by $75.0 \%$ of farmers cultivating BU dhan 1 , followed by the less market value of the product $(67.5 \%)$. The infestation of pest and disease were identified as the third problem for BU dhan1 growers (37.5\%), where these problems were considered as the major problem for BU Hybrid lau1 growers (78.0\%). Most of the respondents claimed severe virus attack. They also noticed that disease infestation caused fracture and rotten roots of plants. Other constraints proffered include high maintenance cost (65.5\%) and lack of training (42.0\%) on BU Hybrid lau1 technology. Farmers provided valuable suggestions during their interviews. Eighty two percent of $\mathrm{BU}$ dhan1 growers mentioned that they frequently need adequate supply of quality seed for better crop yield. They also included improvement of marketing facilities (74.5\%), pest control $(42.0 \%)$ and regular training and field visit $(28.5 \%)$ in their suggestion. The BU Hybrid lau1 growers suggested the need for development of virus resistant variety as their 1st priority (82.5\%), followed by disease-free seed supply (74.0\%) and effective training facilities (45.0\%).

\section{Salient Features of Technologies}

Results obtained from focus group discussion are showed in Figure 2. In the diagram, the salient features of BSMRAU technologies (BU dhan1 and BU Hybrid lau1) were identified. In terms of BU dhan1, the good features were:(1) short duration with medium yield;(2) soft straw and more preferable for cow;(3) suitable for muri (Puff rice);(4) less irrigation, (5) low disease and insect infestation; (6) bright rice color; and (7) soft when cooked. Besides, BU Hybrid lau1 possess some suitable features

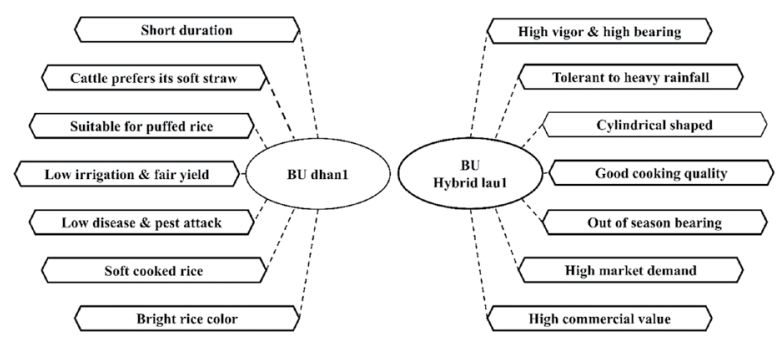

Figure 2. Salient features of two BSMRAU technologies (2 FGD, n= 10 participants per technology)

such as (1) high vigor;(2) tolerant to frequent rainfall; (3) high yielding;(4) Cylindrical shaped, (5) Good cooking quality, (6) out of season bearing. BU lau1 has high market demand and market value. According to the FGDs, all identified qualities of two BSMRAU technologies were acceptable for farming.

In low-income countries like 
Table 4.

Identified Problems and offered Suggestions for both BSMRAU Technologies

\begin{tabular}{|c|c|c|c|c|c|c|}
\hline \multirow{2}{*}{ Innovation } & \multicolumn{6}{|c|}{ Respondent } \\
\hline & Problems & $\%$ & Rank & Suggestions & $\%$ & Rank \\
\hline \multirow{4}{*}{ BU dhan1 } & $\begin{array}{c}\text { Presence of dried empty } \\
\text { grain. }\end{array}$ & 75.0 & 1st & $\begin{array}{l}\text { Sufficient seed supply } \\
\text { in time }\end{array}$ & 82.0 & $1 s t$ \\
\hline & Low market price & 67.5 & 2nd & $\begin{array}{l}\text { Improve marketing } \\
\text { facilities }\end{array}$ & 74.5 & 2nd \\
\hline & $\begin{array}{l}\text { Pest and disease } \\
\text { infestation }\end{array}$ & 37.5 & $3 r d$ & Pest and disease control & 42.0 & $3 r d$ \\
\hline & Lower yield & 25.0 & 4th & $\begin{array}{l}\text { Provide training and } \\
\text { field visit }\end{array}$ & 28.5 & 4th \\
\hline \multirow{3}{*}{$\begin{array}{l}\text { BU Hybrid } \\
\text { lau1 }\end{array}$} & $\begin{array}{l}\text { High pest and disease } \\
\text { infestation }\end{array}$ & 78.0 & 1st & $\begin{array}{l}\text { Development of virus } \\
\text { resistant variety }\end{array}$ & 82.5 & 1st \\
\hline & High maintenance cost & 65.5 & 2nd & $\begin{array}{l}\text { Disease free seed } \\
\text { supply in time }\end{array}$ & 74.0 & 2nd \\
\hline & $\begin{array}{l}\text { Lack of training on this } \\
\text { technology }\end{array}$ & 42.0 & 3rd & $\begin{array}{l}\text { Provide training and } \\
\text { field visit }\end{array}$ & 45.0 & $3 r d$ \\
\hline
\end{tabular}

Bangladesh, adoption of improved agricultural technologies and production practices are important drivers for getting good agricultural return. (Kumar et al.,2020). BU dhan1 may play a crucial role in meeting required nutrition to the people as a main food of Bangladesh. It has some good attributes such as 'short duration,'soft straw', 'required less irrigation', 'low disease and insect infestation' (Figure 2). In contrast, this rice variety is less pricy in the market and it gives dry empty grains (Table 4). Information shown in Table 1 reveal that the performance of the rice variety (BU dhan1) is very good. Overall, farmers were compelled to adopt the BU dhan 1 for high profit as because their knowledge gap was also found low in terms of crop cultivation for deciding the right innovation (Table 2; Table 3). Generally, education and sound knowledge always assist farmers to decide adopting a new idea or technology quickly (Sakib et al., 2019)

In contrast, Hybrid lau1 has good market demand, this might take place because of its high nutritious value, good cooking quality, and availability (Figure 2). However, the adoption rate is quite low in the study area. Information source namely mass media plays a vital role to make a good variety popular to the farmers (Sakib et al., 2019). In fact, majority (60.0\%) had been cultivating the Hybrid lau1 for only one year (Table 2). However, personal discussion between farmers about the technology will increase with the increase of Hybrid lau1 farming period. In case of Hybrid lau1, disease tolerant plants and pathogen 
Assessing the Overall Efficiency of two technologies of Bangabandhu Sheikh Mujibur Rahman Agricultural University, Bangladesh

free seeds were required for getting a wide acceptance of this technology (Table 4). Farmers training will improve the culture of the Hybrid lau1 for a high profit in farms and modern extension strategies can play a vital role to disseminate the technologies.

\section{CONCLUSION}

This investigation provides an idea that farmers had different level of adoption for these two specific BSMRAU technologies in their field, i.e. high adoption for BU dhan1 but low for BU Hybrid lau1. Hence, extension agencies should be geared up and continue their efforts including organizing different farmers' training programmes so that they can develop self-confidence in them to take up rice technologies with some minor crops for a profitable co-cultivation, not only for improving their farm production and income but also inspiring others to do the same. So, there is an urgent call for the extension agencies and other concerned departments to handle the crucial factors like increment on annual income, increasing yield, lessening complexities with farming practices and reducing knowledge gap in order to bring positive farmers' perceptions to these technologies. It can also be suggested that these significant attributes should get more emphasis and attention through continuing efforts while formulating different development strategies and programmes for farmers.

\section{REFERENCES}

Adnan, M. S. G, Abdullah, A. Y. M, Dewan, A, \& Hall, J. W. (2020). The Effects of Changing
Land Use and Flood Hazard on Poverty in Coastal Bangladesh. Land Use Policy, 99, 104868.

Alamgir, M, Mohsenipour, M, Homsi, R, Wang, X, Shahid, S, Shiru, M. S, Alias, N. E, \& Yuzir, A. (2019). Parametric Assessment of Seasonal Drought Risk to Crop Production in Bangladesh. Sustainability, 11(5), 1442.

Guo, S, Jiang, L, \& Shen, G. Q. (2019). Embodied Pasture Land Use Change in China 2000-2015: From the perspective of globalization. Land Use Policy, 82, 476-485.

Kabir, M. E, Davey, P, Serrao-Neumann, S, \& Hossain, M. (2018). Seasonal Drought Thresholds and Internal Migration for Adaptation: lessons from Northern Bangladesh. In Pathways to a Sustainable Economy, pp. 167-189, Springer, Cham.

Kumar, A, Takeshima, H, Thapa, G, Adhikari, N, Saroj, S, Karkee, M., \& Joshi, P. K. (2020). Adoption and Diffusion of Improved Technologies and Production Practices in Agriculture: Insights from a donor-led intervention in Nepal. Land Use Policy, 95, 104621.

Leya, R. S, Saha, D, Bala, S. K, \& Huq, H. (2020). Gender Vulnerability Assessment due to Flood in Northern Part of Bangladesh: a case study on 2017 Flood. In Water, Flood Management and Water Security under a Changing Climate, pp. 235-249, Springer, Cham.

Nasim, F. A, Hoque, M. Z, Haque, M. E, Islam, M. S, Parveen, N., Chakma, S, \& Afrad, M. S. I. (2019). How does adoption of crop 
variety reduce the impact of drought in agriculture and mitigate food insecurity of smallholder farmers? A case study on BUdhan1 rice variety in Bangladesh. Asian Journal of Agricultural Extension, Economics \& Sociology, 30(3), 1-12.

Naznin, M, Afrad, M. S. I., Haque, M. E., Zakaria, M., \& Barau, A. A. (2018). Perception of Rural Farmers on Pesticide Use in Vegetable Production. Agricultural Science and Technology, 10(2),115-120.

Nyumba, T, Wilson, K., Derrick, C. J., \& Mukherjee, N. (2018). The Use of Focus Group Discussion Methodology: insights from two decades of application in conservation. Methods in Ecology and evolution, 9(1),20-32.

Quddus, A \& Kropp, J. D. (2020). Constraints to Agriculture Production and Marketing in the Lagging Regions of Bangladesh. Sustainability, 12(10), 3956.
Rao, M. B. (2016). Motivation of teachers in higher education. Journal of Applied Research in Higher Education. 8(4), 469-488.

Rogers, E.M. (2003). Diffusion of Innovations, (5th ed.). Free Press, New York, p221.

Sakib, M. H, Reza, A, Afrad, M. S. I, \& Lee, S. G. (2019). Socio-Economic Factors Responsible for Adoption of Alien Fish Species by Fish Farmers in Bangladesh. The Journal of Social Sciences Research, 5(2), 577-582.

Wanfu, J, Chunshan, Z, Tao, L, \& Guojun, Z. (2019). Exploring the Factors Affecting Regional Land Development Patterns at different Developmental Stages: Evidence from 289 Chinese cities. Cities, 91, 193201.

Zinat, M. R. M, Salam, R., Badhan, M. A, \& Islam, A. R. M. T. (2020). Appraising Drought Hazard During Boro Rice Growing Period in Western Bangladesh. International Journal of Biometeorology, pp. 1-11. 